\title{
FUTURE MANAGEMENT FOR INCREASED PRODUCTIVITY
}

\author{
By A. P. MacBEAN ${ }^{1}$
}

The importance of the forest industries to the Canadian economy is only natural considering the extent of land surface unsuited to agriculture. It may not be recognized by all citizens, but it is hardly likely that there are any in this group who do not have a full appreciation of the contribution of the forests to the welfare of the nation.

The net value of pulp, paper, lumber, plywood and a multitude of other products reached $\$ 2.4$ billion in 1960 . In considering this statistic, it is of interest to note that the Gordon Commission, in its 1957 report on Canada's Economic Prospects, predicted that the value of production from the primary forest industries would more than double in the 25 years from 1955 to 1980 . The statistics of recent years show that the value of production is under the predicted level, in the range of 13 to 18 percent.

The forest industries account for 10 percent of the Gross National Product which has been indicated at $\$ 45$ billion in 1964 . The pulp and paper mills alone exceed all other manufacturers in sales value. On the basis of gross product value forestry is only exceeded by agriculture and mining.

Forest products with a value of over $\$ 1.5$ billion make up 29 percent of total exports from this country. In this respect their contribution towards achievement of a favourable trade balance is well ahead of any other industry.

Five percent of the total labour force, or over 300 thousand people, are employed in the woods, pulp and paper mills, sawmills and other woodusing industries.

The dominant position represented in this short review has been attained with a minimum of forest management - in this sense meaning without the forestry practices applied in the classic European model. In making this comparison there has been no intent of minimizing the very real progress, which has been made in certain fields over the past quarter century. Notable examples include fire protection, utilization, reforestation and inventory.

Basically we are still engaged in the process of liquidating an enormous natural forest, which with limited exceptions is becoming more distant from the mills. The close-in areas have often suffered recurring fires. Following logging most young stands have originated from natural seeding. Irregular spacing is common, and large areas are occupied by non-commercial species.

Since 1945 Canadian timber production has increased by only 21 percent to the 1961 level of 3.3 billion c.f. In this period British Columbia production has more than doubled, having moved from 19 to nearly 35 percent of the national total. This percentage probably would be higher if the most recent Canadian statistics were available.

${ }^{2}$ Chief Forester, MacMillan, Bloedel and Powell River Limited, Vancouver, British Columbia. 
At the start of this period (1946) there still was a large undeveloped, but accessible forest in British Columbia, particularly in the Interior of the Province. In the eastern provinces the easily accessible forest had been pushed back, and with existing methods of extraction new development, save for scattered exceptions, was restricted.

Since the early part of this century foresters have been employed in a variety of activities by both government and industry. For the most part they were engaged in fire protection, administration of timber sales, cruising, and wood production. It is only recently that they have become engaged on a large scale in the growing of a new crop.

This is evident from the increasing scale of artificial reforestation. In B.C. the acreage planted in 1939 was just over a thousand acres, and the total, including that year, was only 2.3 thousand acres. In 1963 nearly 39 thousand acres were planted, of which half was by industry or other private effort. The accumulated total at that year was 294 thousand acres.

Comparable Canadian statistics have not been found, although it is believed that a similar situation exists in a few of the other provinces. For instance, in Ontario 49 thousand acres were planted in 1962.

Considering the relatively low level of cutting in relation to a seemingly limitless resource of prime timber there was little need for regulation of the cut, nor for the other practices associated with sustained yield.

Since the second World War the adoption of sustained yield management has spread widely and rapidly through the country. Working plans now apply to large forest areas. Unless accompanied by more intensive forestry practices and fullest utilization, this form of management will soon limit the possibility of increased production.

By regulating the cut to existing conditions the initial working plans will ensure perpetuation of the present industry at current levels, but little more. These plans accept slow regeneration, relatively poor stocking and less than full utilization. With isolated exceptions there has been little provision to increase yield, nor to recognize in allowable cut calculations the form of future utilization, which has a most important bearing on the rotation period employed.

Justification for increasing the allowable annual cut must be based on a number of criteria including the sound appraisal of opportunities to economically convert and sell this additional wood. Although Canadians have the highest annual per capita rate of consumption of forest products, estimated at 76 c.f., exclusive of fuelwood, we use less than half of the total wood produced. The balance is exported.

Traditionally we have been exporters selling into all the principal markets of the world, but in particular the United States, United Kingdom, Europe and Commonwealth countries. A quick look forward will help to establish our prospects.

American authorities forecast a large increase in the consumption of forest products during the next 35 years. Some analysts anticipate that most of these new needs will be met from their own resources. The share which Canada can expect is conditional on a number of factors, but probably most important is our ability to trade at competitive prices. 
The two most important timber producing regions of the United States are the west and south. In both areas intensive forestry practices are being applied on an increasing scale. The south has shown the most dynamic changes. In the 20's it was freely predicted that the region, after being for a long time an important lumber producer, would cut out. Since then a large pulp and paper industry has been founded on second-growth pine. Large-scale planting programmes, the conversion both of former cotton fields and of low-yielding hardwood lands to pine, are providing the basis for expansion, particularly in pulp and paper, but also lumber.

The magnitude of change is evident from a comparison of wood pulp statistics. In 1939 the southern states produced 3.7 million tons, which was less that the Canadian total of 4.2 million tons. In 1962 southern production, at over 16 million tons, exceeded all of Canada, having increased by 350 percent compared with only 190 percent in this country.

At the time of the Roman occupation the United Kingdom was heavily forested. By the First World War Britain was heavily dependent on imports. Subsequently the remaining small timber resource was heavily depleted by two world wars. A critical supply situation developed during the first war, and as a result the United Kingdom adopted a reforestation policy aimed at producing ultimately about half of the nation's wood requirements. The present Forestry Commission was established to secure this objective. In addition, incentives have been instituted to encourage forestry on private estates.

Europe has been under sustained yield management for a long period and until recently was largely self-sufficient. The timber-deficient countries have met their needs from Scandinavian and Russian sources. Under a buoyant economy, and in spite of increasing yields, gained by the widest application of intensive forestry practices, early wood deficits are predicted.

Lumber and other timber has been exported from Russia to Europe over a long period. Mostly this wood is produced in the European section of the U.S.S.R. Because of their own needs and also because of past overcutting in the European section, it is unlikely that exports will rise significantly. The main part of the vast U.S.S.R. timber resource fortunately lies east of the Urals in Siberia, where high transportation costs rules out exports of any consequence.

Although importations have been on a relatively small scale, nevertheless the Commonwealth countries have been important customers for Canadian wood products. Significant changes have been developing.

New Zealand was heavily timbered when first settled, but this forest was largely destroyed to make way for agriculture. The folly of this action was finally recognized and in the 20's and 30's large-scale afforestation was undertaken, so that now New Zealand has nearly a million acres in radiata pine, and other conifers, with Douglas fir of second importance. The growth rate ( m.a.i.) is nearly 12 times that of much of Canada, and is realized on onethird of the rotation employed here. As a result New Zealand is now a net exporter of pulp, paper and lumber.

Australia was poorly endowed with commercial forests, but like New Zealand has taken steps to meet its needs by planting fast-growing pines. Under the stimulus of protective tariffs the plantation forests now cover more than 400 
thousand acres and continue to be extended. It is unlikely that Australia will completely meet her requirements, due to shortage of suitable land and to increasing population.

South Africa, including Swaziland, was also poorly endowed with indigenous forest suitable for timber production. Over a fairly long period nearly $\mathbf{2 . 2}$ million acres have been planted in exotics, including wattles, eucalypts, and fast-growing pines. As in New Zealand and Australia, the growth of pine is fantastic by Canadian standards. In spite of these developments there is some opinion that importation will continue on a modest scale.

Highly industrialized Japan, small in area but with a large population, has experienced, like western Europe, a rapidly expanding economy since 1945. The forest area is relatively small and has been seriously overcut. To meet her needs and restore her forests Japan must continue to import timber and pulp, probably in increasing quantities. These needs are currently supplied from the west coast of North America, New Zealand, the Pacific Islands and the Far East of the U.S.S.R.

From this brief sketch it should be apparent that there is an opportunity for expansion of sales beyond our borders. However, there should be no illusions, since the requirements of these countries as well as others can be met from a number of alternative sources. More than one factor will determine our future prospect, but high on the list will be our ability to provide new wood sources at low cost.

It is true that there are still extensive virgin forests in the northern parts of Canada waiting for development, but this timber will suffer high transportation and other costs.

It is my contention, which is not held to be original, that the application of intensive forestry to areas lying within 50 road or equivalent miles of existing mills will in many cases be more economic. Frequently the best growing sites lie within this radius, but for a variety of reasons the growth capacity is not being realized because of past neglect.

This situation poses a great challenge to Canadian foresters to influence the development of wise policies, which will result in profitable expansion of forest production. Since about 90 percent of Canada's productive forest lands have been retained in Provincial Crown ownership, the responsibility falls most heavily on foresters in the employ of the Provincial authorities. However, industrial foresters must also play a part since under various forms of agreement industry has undertaken forest management commitments over large areas.

Although other regions could be selected the southern coast of British Columbia is chosen, because of familiarity with it, to illustrate the possibilities of intensive management. For purposes of public administration the area is defined as the Vancouver Forest District. Here, at the beginning of the 19th century, the earliest logging in the Province took place. It still supports the highest level of all forms of forest production. During the past five years the scale of timber cut has exceeded 600 million c.f. annually. This is exclusive of the almost complete recovery of pulp chips from sawmill and plywood residuals - estimated to exceed the equivalent of over 160 million c.f. of logs. Over 65 percent of the forest is now under sustained yield management. 
More than half of this area is in either Tree-Farms or Tree-Farm Licences and managed privately. The balance is in Public Sustained Yield Units under the direct control of the Forest Service.

This region, including the areas not yet covered by Working Plans, is probably slightly overcut if one accepts the generally conservative approach currently employed in calculating the allowable cut. This statement also recognizes the fact that complete utilization in the woods has been achieved over only part of the acreage currently being logged. In addition forestry practices are still generally extensive with reliance on natural regeneration over large areasthis is in spite of the large increase in planting operations, which was noted earlier.

By the adoption of intensive forestry practices, increased utilization of the residuals after sawlog operations, and of shorter rotations it is estimated that the allowable cut could be increased by at least 25 percent.

Since 1945 the large integrated companies, in varying degrees, have made notable progress in managing the timberlands, which they either own or else control by agreement. Management objectives include:

a) The organization of logging on a year-round basis to ensure stable communities. This is being achieved by careful long-range planning to balance summer and winter logging shows.

b) High protection standards to ensure minimum losses of both immature stands and mature timber.

c) Full utilization of the present timber crop through recovery of logging residuals for pulp production. A variety of methods are employed relogging, pre-logging, or full recovery in a single pass.

d) The application of intensive forestry programmes to gain maximum growth from every acre in the shortest practical rotations.

Practices currently employed include:

a) Prompt planting - allowing only 2 years for natural reseeding.

b) Fill planting, where planting or natural failures occur.

c) Site treatment, by scarification or reforestation burns to improve the chance for uniform spacing and higher plantation survival.

d) Juvenile spacing or thinning to achieve uniform wide spacing - the equivalent of planting.

e) Control of alder and brush to ensure full stocking of more valuable coniferous species.

f) Commercial thinning to recover suppressed trees, which would be lost before the final harvest, also to improve the quality of the final crop.

g) Stand rehabilitation by conversion of low m.a.i. stands, to be replaced by new vigorous growth.

Experimental work with fertilizers has been in progress for 10 years. Almost immediate growth response is obtained by the application of fertilizers containing nitrogen. The question remaining to answer is whether the stimulus will be sustained for a sufficient time to return the investment. At this date the indications from the earliest plots suggest that the application of fertilizers will have a good chance of being economically successful.

In reaching a decision as to the desirability of embarking on intensive forestry the cost of such a programme cannot be ignored. Whether it be 
government or industry, careful consideration must be given to an investment which, except from intermediate thinnings, cannot be recouped for a period of from 60 to 100 years.

The classical test is to treat the cost of reforestation and other treatments as an investment. Planting, tending, taxes and other charges, as well as the early returns from thinning are carried forward at compound interest. The test of acceptability is the accumulated cost in relation to the overall stumpage value of the forest at maturity. Generally these calculations show the rate of return to be marginal.

A going concern may treat forestry expenditures as a current operating charge. If this course is followed an intensive forestry programme may be justified by the value of an early increase in the level of allowable cut. resulting from higher growth rates and larger acreages in growing stock. The result is higher earnings, which can be obtained within a comparatively few years of instituting the programme.

Where large areas of old growth forest still exist, and this is still the situation on the British Columbia coast, it is particularly desirable to liquidate rapidly, whether or not a sustained yield policy is in effect. Over-mature timber, with a declining volume, is replaced by young thrifty stands.

Even though the concept of treating cost as an operating expense is accepted, it nevertheless is necessary for the forest manager to have guidelines, to determine the location, the minimum acceptable growing site, and the nature and priority of treatments. For this purpose there is no substitute for economic analysis employing compound interest.

There are other factors of concern to anyone contemplating investment in forestry. Earlier in this paper the question of future market possibilities was considered. In addition to these items there is a very real concern as to how much wood will be required in the future or whether it will be required at all. There is no sure answer to the question "will technological developments, now unforeseen, provide more desirable substitutes " - there are likely to be some.

The per capita consumption of lumber has been declining over a long period. In Canada it has dropped in 50 years from 450 f.b.m. in 1913 to 165 f.b.m. in 1963. A comparable trend has occurred in the United States of America. Due to increasing population overall consumption has not shown the decline, and fortunately for Canada the volume of lumber exported has risen.

Plywood, which was unknown in 1913, has now reached a per capita use of 57 sq. ft. $\left(3 / 8^{\prime \prime}\right)$.

Over a comparable period the use of paper and paper board has increased from 37 to 293 lbs. per person. This trend is duplicated in all of the advanced industrialized countries.

The pulping of wood for the manufacture of paper and paper board products is a relatively new development. The first groundwood was made in Europe in 1844, but manufacture in North America did not start until 1867, just short of 100 years ago. Sulphite followed in 1888 and sulphate in 1907. Because of superior qualities and generally wider acceptance of species, the latter is now in favour and may in time supersede sulphite. 
Dissolving pulps for rayon were first made in Canada in 1923. They were in great demand, but have declined since nylon was introduced, starting in 1939 in the United States.

In the past 25 years, the use of wood for fuel has almost disappeared in many areas. Its place has been taken by relatively cheap supplies of the more convenient to use fuels such as natural gas and oil. In time these will disappear.

For the next 20 to 30 years the growth of population appears to assure an increasing timber requirement. Beyond that time there is no sure way of forecasting - certainly not for a crop which requires 60 to 100 years to maturity.

In the days of sailing ships oak was in great demand and there was much concern in England for future supplies. Now, because of the long rotation required, no-one would plant it for a commercial crop.

Foresters frequently are concerned as to the choice of species. Recent development in pulping, and the innovation of particle and chip boards, has made this question less important. Species such as western hemlock, jack pine and lodgepole pine, which only a few years ago were used in only limited volumes, are now in great demand.

Where planting or artificial seeding, must be undertaken, or where other control can be exercised, the answer would appear to be long-fibre conifers. The goal should be fast growth on the shortest possible rotation.

If forest management is to be directed to increased productivity then it is certain that more trained people will be required to provide foremen, technicians, engineers and foresters.

Both federal and provincial research agencies must redirect and expand their programmes to provide early answers to silviculture, growth and yield, as well as other problems of establishing and tending the new crop. These organizations could benefit from the advice of industry, which could be provided through regional advisory committees.

The public generally has come to accept the principle of sustained yield forestry. The adoption by government of overly conservative forest management policies could be just as dangerous as radical policies.

The forest industries have long held an important position in the Canadian economy. The value of forest products exported is unrivalled by any other industry.

The future welfare of the country will benefit greatly by the adoption now of philosophies that will advance our position in the world forest products market. 